\title{
Materials Response to Glancing Incidence Femtosecond Laser Ablation
}

\author{
McLean P. Echlin ${ }^{\mathrm{a}}$, Michael S. Titus ${ }^{\mathrm{a}}$, Marcus Straw ${ }^{\mathrm{b}}$, Peter Gumbsch ${ }^{\mathrm{c}, \mathrm{d}}$, Tresa M. Pollock ${ }^{\mathrm{a}}$ \\ ${ }^{a}$ Materials Department, University of California - Santa Barbara, Santa Barbara CA 93106-5050, USA \\ ${ }^{b}$ FEI Company, Hillsboro, OR, USA \\ ${ }^{c}$ Institute of Applied Materials (IAM), Karlsruhe Institute of Technology, Germany \\ ${ }^{d}$ Fraunhofer IWM, Freiburg 79108, Germany
}

\begin{abstract}
A femtosecond Ti:sapphire laser was used to ablate samples of copper, strontium titanate (STO), a nickel alloy René 88DT (R88), $\{111\}$-oriented single crystal silicon, and gallium nitride (GaN) in situ in a focused ion beam scanning electron microscope (FIBSEM). The laser beam was scanned parallel to the specimen surface, which resulted in laser ablation using the tail of the Gaussian beam distribution, near the ablation threshold for each of the materials. Transmission electron microscopy (TEM) and electron backscatter diffraction (EBSD) were utilized to investigate damage in the bulk and at the surface of the laser ablated samples in cross-sections that were extracted by FIB-SEM. In contrast to normal incidence, post-ablation damage in the glancing incidence configuration was extremely limited across a wide range of laser pulse energies. Elevated dislocation densities were observed within 150-200 $\mathrm{nm}$ of the ablated surface in the Cu, STO, and R88 samples. An amorphized Si layer as thin as 30-50 nm was observed with no dislocations near the surface or in the bulk. Gallium nitride exhibited exceptional damage resistance to femtosecond laser irradiation, whereby no laser-induced dislocations or amorphization near the ablated surface was observed. For materials where there is surface damage following laser ablation, we show that a subsequent machining step with a Ga ${ }^{+}$FIB beam located in the same chamber can remove this damage in a short period of time.
\end{abstract}

Keywords: femtosecond laser, silicon, transmission electron microscopy, amorphization, focused ion beam, GaN, gallium nitride, copper, $\mathrm{Cu}$, Nickel, Ni, $\mathrm{STO}, \mathrm{SrTiO}_{3}$, strontium titanate

\section{Introduction}

Femtosecond lasers have enabled new pathways for surface texturing and rapid material removal across many materials systems [1-8]. Femtosecond laser induced material removal also allows for chemical analysis of the ablating species via light induced breakdown spectroscopy [9, 10]. For specific experimental geometries, the resulting low-fluence femtosecond laser pulses used to ablate material result in very low damage surfaces that are amenable for direct imaging for emerging tomography techniques. This enables 3D mesoscale materials characterization with nm-scale resolution and multiple chemical, structural, and crystallographic imaging modalities [11, 12].

The unique low damage nature of ultrashort pulsed lasermaterial interactions are a result of the large impulse of energy (mJ pulse energies) tightly focused onto the sample surface over time periods often substantially less than $500 \mathrm{fs}$. Kinetic transport and the ablation processes do not begin to occur until long after $(>100 \mathrm{ps})$ the laser pulse has been deposited [13-15]. The large amount of energy deposited into the structure over such short time scales suppresses large scale structural damage and melting in crystalline and amorphous materials because the interaction is mostly confined within the electronic structure of the material [16, 17]. The difference in thermalization time between the electronic structure and the lattice significantly re-

Email address: mechlin@engineering.ucsb.edu (McLean P. Echlin ) duces the extent of thermal damage surrounding the ablation event [4, 13].

The mechanisms by which material is removed during femtosecond laser ablation and the resulting forms of damage are dependent on the absorbed fluence on the target and the material properties. Under beam-normal to surface incidence conditions, distinct transitions in the type of damage and laser ablation rates are observed across fluence thresholds in many materials. Transitions in damage type occur as the ablation threshold is crossed [2, 18, 19] and with the crossing from low fluence to high fluence threshold [6, 20]. The values of these discrete thresholds depend on the optical penetration depth and the electronic heat conduction within the irradiated material, which have been studied in detail for some metals [19]. For instance, laser ablated metals may experience dislocation injection [5, 21, 22], phase changes [23], or recrystallization [24] during laser ablation. However, semiconductors are observed to amorphize [2], recrystallize [25], exhibit phase changes [26], and generate dislocations [27] under certain laser processing conditions. Dielectrics respond differently by not exhibiting discrete changes in the rate of material removal during ablation [8, 28] - likely due to their low thermal conductivity.

Femtosecond laser ablated surfaces have been studied using a range of analytical techniques. These include optical microscopy [29], scanning electron microscopy (SEM) [5, 20], 
electron backscatter diffraction (EBSD) [21, 22], and transmission electron microscopy (TEM) [5, 30, 33] imaging of the ablation region resulting from single laser pulses impinging with normal incidence to the sample surface. For most materials, melting occurs at very high fluences, often near the peak of the Gaussian beam with regions of high dislocation densities or amorphization radially surrounding the high fluence region of the pulse. In contrast, laser ablation at glancing incidence to the sample surface limits laser pulse energy deposited at the material removal interface to low fluences near the ablation threshold. This results in low levels of damage [5, 31, 33], though damage resulting from glancing incidence irradiation has not yet been studied in detail. In this research, results of damage studies performed on a series of laser ablated materials, including metals, semiconductors, and ceramics with glancing incidence ablation are presented. These different materials classes were methodically examined using consistent experimental methodologies and characterization approaches.

\section{Experimental}

Samples of annealed oxygen-free high conductivity (OFHC) $\mathrm{Cu}$, strontium titanate (STO), a Ni-based superalloy René 88DT (R88), Si, and GaN were irradiated using the TriBeam [12], which is a FIB-SEM microscope with in-situ femtosecond laser capability. A Ti:sapphire gain medium femtosecond laser operating at $780 \mathrm{~nm}$ wavelength, $1 \mathrm{kHz}$ repetition rate, and $150 \mathrm{fs}$ pulse width was used to ablate sample surfaces in the TriBeam FIB-SEM vacuum chamber at a pressure of $4 \times 10^{-6}$ mbar. The laser beam propagation direction was aligned parallel with the sample surfaces and then scanned laterally, as shown schematically in Figure 1. The stage on which the sample is mounted is composed of piezoelectric driven nm-resolution actuators (X, $\mathrm{Y}, \mathrm{Z}$, tilt) that permit material removal by incrementally moving the sample surface into the scanning beam path, shown in Figure 117. The TriBeam system and the femtosecond ablation process is described in more detail elsewhere [34].

The sample surfaces were incrementally laser machined with a scanned beam by raising the specimen using the z-positioner of the piezo substage at micron to sub-micron step sizes. The femtosecond laser beam is tightly focused into a spot diameter of $15-35 \mu \mathrm{m}$ with a Gaussian profile. The beam is scanned horizontally, as shown in Figure 19 and b, with $75 \%$ spot overlap in the beam scanning direction. The beam is scanned across the surface with a width up to $1.2 \mathrm{~mm}$ for $100-200$ lateral passes in order to remove all material within the focused and scanned beam region that is above the ablation threshold $\left(\theta_{t h}\right)$, the point at which vaporization occurs [35]. The location of the ablation threshold along the radial edge of the Gaussian beam is shown schematically in Figure $1 \mathrm{~b}$. As a result, the tail of the Gaussian beam profile that has fluence at or very near the ablation threshold of the material, is the only part of the beam interacting with the final sample surface. The removal rate as a function of beam fluence is shown in Figure 1 c for laser pulses across a wide range of fluences in a nickel base superalloy [20]. Laser machining with the beam parallel results in irradiation fluences at or near the ablation threshold, which is a property unique to each material [36]. The focusing optics have a depth of focus of $0.98 \mathrm{~mm}$. The sample surface was incrementally raised with the piezo stage z-positioner with $1 \mu m$ steps into the tail of the Gaussian beam between laser beam scanning operations. The sample surfaces were milled at least 50-100 $\mathrm{mm}$ (50-100 slices) in depth. The laser machining procedure used in this study is in contrast to other single pulse type laser machining studies or hole drilling, where the laser beam propagation direction is orthogonal to the sample surface that experiences the full Gaussian distribution of the beam energy.

Measurements of the light induced periodic surface structure (LIPSS) wavelength were made from secondary electron SEM images collected from the laser machined sample surfaces. The LIPSS structures form with their long axis oriented orthogonal to the linear polarization vector of the laser light [2, 37,-39], which has been chosen such that the long axis of the LIPSS structures is also orthogonal to the propagation direction of the laser beam. The amplitude of the LIPSS structures were additionally measured in the TEM lamellae extracted from the laser machined sample surface. The long axis of the lamellae was oriented to be orthogonal to the prevailing LIPSS structure orientation, therefore capturing a cross-section of the LIPSS wavelength where the damage is observed to vary somewhat between the maximum and minimum amplitude. A summary of the LIPSS wavelength and amplitude measurements, using SEM and TEM, are given in Table 1 .

Electron backscatter diffraction (EBSD) maps were collected from the laser machined surfaces surrounding the lift-out areas using a FEI Quanta 3D FIB-SEM equipped with an EDAX Hikari XP EBSD in order to determine the crystallographic orientations of the grains contained in the TEM foils. Grain orientation information was collected directly from the laser ablated surfaces with a $0.5 \mu \mathrm{m}$ resolution at $70^{\circ}$ tilt relative to the $25 \mathrm{keV}$ electron beam operating at a 3-30 nA beam current.

TEM analysis was carried out on lamellae extracted from the laser ablated surfaces in each sample to determine the extent of subsurface damage. TEM specimens were extracted from the samples using a FEI dual-beam Helios Nanolab 600 FIB-SEM equipped with a tungsten Omniprobe needle for lamella extraction. In order to ensure that ion damage or implantation did not occur on the specimen surface, the TEM lamellae were protected with approximately $500 \mathrm{~nm}$ of electron beam deposited $\mathrm{Pt}$, followed by an additional $1.5 \mu \mathrm{m}$ of ion-beam deposited Pt. The TEM lamella were investigated using a FEI T20 TEM operated at $200 \mathrm{keV}$ in both conventional bright-field and dark-field imaging modes.

EBSD information was also collected from the $\mathrm{Cu}$ TEM lamella to quantitatively determine misorientation gradients that can result from laser irradiation. These scans were performed with the samples tilted to $70^{\circ}$ relative to the $30 \mathrm{keV}$ electron beam operating at a $0.5-5 \mathrm{nA}$ beam currents and collected with $0.5 \mu \mathrm{m}$ in plane resolution.

In order to investigate methods to remove small-scale material damage from near-surface regions the STO, nickel alloy, and Si specimens were also milled after laser ablation using a near glancing angle $\mathrm{Ga}^{+}$focused ion beam at the accelerating voltages and beam currents shown in Table 2 TEM lamellae 
were extracted from the laser ablated and ion milled regions using the same protocol as detailed for the laser ablated surfaces. Detailed analysis of the near-surface damage resulting from the laser ablation and FIB milling are presented here, and protocols for the further reduction of damage in each class of material are discussed.

\section{Results}

All the materials investigated exhibited surface structuring via light-induced periodic surface structures (LIPSS), and most materials exhibited some form of near-surface solid-state damage that may include dislocation generation, recrystallization, or low angle boundary formation. LIPSS are a well-known phenomenon resulting from the interactions of pulsed laser light with materials [38, 40, 41]. In the following section we present detailed analysis performed on each material in order of ascending critical resolved shear stress (CRSS) for dislocation motion, given that dislocations were the primary defect introduced.

\subsection{Copper}

Analysis of the $\mathrm{Cu}$ specimen revealed LIPSS with a wavelength of $342 \mathrm{~nm} \pm 55 \mathrm{~nm}$ from peak to peak, as shown in Figure $2 \mathrm{a}$, and amplitude of $323 \mathrm{~nm} \pm 102 \mathrm{~nm}$. The location of the extracted TEM lamella is shown in Figure $2 \mathrm{p}$. The $\mathrm{Cu}$ TEM lamella revealed dislocation damage that extended in some regions to $5 \mu \mathrm{m}$ below the specimen surface, as shown in Figure 22. A bright field condition near a zone axis was chosen to image the lamella in near surface regions in Figure 2 . Crystallographic rotations (bend contours) were observed in 1 to $4 \mu \mathrm{m}$ of the specimen surface. These crystallographic rotations presumably result from high dislocation densities. Individual dislocations were not characterized due to the high dislocation density and large crystal lattice rotation near the specimen surface. Significant differences in the dislocation densities between the two grains was not clearly discernible in the TEM images.

The lattice rotation was measured by convergent beam electron diffraction (CBED). Both grains exhibited lattice rotations ranging from $0.2-3.0^{\circ}$ when measured from the bulk to the surface. The near surface regions in the TEM lamella shown in Figure 2f exhibited rotations of about $0.5-1.5^{\circ}$ in the $1-2 \mu \mathrm{m}$ below the surface, as measured using TEM. EBSD was also performed on the identical TEM foil. The inverse pole figure (IPF) and image quality (IQ) maps from the EBSD data in Figure $2 \mathrm{~d}, \mathrm{f}$ show the same grain orientation and surface morphology measured by TEM. Grain reference orientation deviations (GROD) were calculated from the EBSD dataset with a step size of 50 $\mathrm{nm}$ and are plotted in Figure 2e. Geometrically necessary dislocation (GND) densities were calculated to be between $10^{15}-10^{16}$ $m^{-2}$ using the methodologies presented elsewhere [21, 42]. A 1-2 $\mu \mathrm{m}$ diameter region near the surface shows misorientation gradients of $4-7^{\circ}$ from the surrounding grain. While twinning has been reported in $\mathrm{Cu}$ samples irradiated at high fluences [43], no evidence of twinning was found in these samples.

\subsection{Strontium Titanate}

An overview of the laser irradiated STO surface is shown in Figure 3a. The LIPSS exhibited a wavelength of $400 \mathrm{~nm}$ $\pm 50 \mathrm{~nm}$ and an amplitude of $74 \mathrm{~nm} \pm 45 \mathrm{~nm}$. The extraction location of the TEM lamella is shown in Figure 3 a, and the corresponding bright field TEM micrograph is shown in Figure $3 \mathrm{~b}$. Within the first $100 \mathrm{~nm}$ of the specimen surface, elevated dislocation densities were observed, which prevented the observation of individual dislocations and the ability to characterize them, as shown in Figure 3 p. However, individual dislocations are present in the grain on the left in Figure $3 \mathrm{p}$ to depths of $1.5 \mu \mathrm{m}$ below the specimen surface. Previous research has shown that these dislocations are of $\langle 110\rangle\{1 \overline{1} 0\}$-type [36], which are the same type frequently observed in mechanically compressed STO specimens [44 47]. These dislocations are not observed in the bulk in the adjacent grain on the right in Figure 3 , which was less favorably oriented for $\langle 110\rangle\{1 \overline{1} 0\}$ type dislocation slip [36].

\subsection{René $88 D T$}

The polycrystalline nickel alloy, René 88DT (R88), forms LIPSS structures during femtosecond laser ablation, which are visible in the SEM images in Figure 4 a, with a measured periodicity of $337 \mathrm{~nm} \pm 58 \mathrm{~nm}$ from peak to peak and an amplitude of $222 \mathrm{~nm} \pm 72 \mathrm{~nm}$. The TEM image in Figure $4 \mathrm{~d}$ shows the LIPSS in cross section in a René 88DT sample, shown in Figure 4p. LIPSS amplitudes ranged from 100 to $300 \mathrm{~nm}$. Elevated dislocation densities were observed near the surface of the LIPSS structures. The dislocation density reduces sharply as a function of depth from the surface in the first 100-200 $\mathrm{nm}$. However, the occasional dislocations visible at depths below 100-300 nm from the surface were scarce. These deep dislocations are characteristic of those that result from material processing and are likely present before laser ablation.

Selected area diffraction TEM imaging revealed occasional recrystallized grains less than $150 \mathrm{~nm}$ in width at a frequency of $1-2$ per $10 \mu \mathrm{m}$, as shown in Figure $4 \mathrm{~b}$ and c. A reciprocal lattice point was used to image the recrystallized grain in dark field mode in Figure $4 \mathrm{c}$, as shown in the diffraction pattern in the figure inset. Recrystallized grains were not resolved in large EBSD surface scans collected directly from the laser ablated surfaces at $0.2 \mu \mathrm{m} /$ pixel or coarser resolutions or by 3-D EBSD reconstructions of the microstructure detailed elsewhere [12]. Thus it is likely that the conditions that enable boundary motion in the recrystallization process were present for only very short periods of time.

\subsection{Silicon}

The femtosecond laser irradiated $\mathrm{Si}$ specimens also contained LIPSS that exhibited a wavelength of approximately $363 \mathrm{~nm} \pm 64 \mathrm{~nm}$, as shown in Figure 57 and elsewhere [2, 48]. The amplitude of the LIPSS in Silicon is $55 \mathrm{~nm} \pm 16 \mathrm{~nm}$. Bright field TEM micrographs of the cross-sectioned areas revealed a $54 \mathrm{~nm} \pm 19 \mathrm{~nm}$ layer of amorphous $\mathrm{Si}(\mathrm{a}-\mathrm{Si})$, as shown in Figure 5 p-e. Convergent beam electron diffraction patterns were obtained in: (c) the electron beam deposited Pt (E-Pt) layer, (d) 
a-Si layer, and (e) bulk crystalline Si. The amorphous diffraction pattern in Figure 5d indicates that crystallinity was lost in this layer, and the pattern differs from that of the nanocrystalline E-Pt layer shown in Figure 5k. Furthermore, TEM energy dispersive X-ray spectroscopy (EDS) measurements confirmed that the a-Si layer was pure Si. The a-Si layer resulting from femtosecond laser ablation did not change in thickness with varied irradiation parameters, including peak beam fluence or number of scan passes. Below the a-Si layer, no dislocations or other signs of damaged material was observed in the bulk material, as shown in Figure 5. This is in contrast to the previous materials ( $\mathrm{Cu}, \mathrm{R} 88$, STO), where high dislocation densities were present within the first $100 \mathrm{~nm}$ of the surface and lower densities deeper into the bulk of the material.

\subsection{Gallium Nitride}

The GaN specimen exhibited $320 \mathrm{~nm} \pm 28 \mathrm{~nm}$ wavelength LIPSS with a amplitude of $177 \mathrm{~nm} \pm 87 \mathrm{~nm}$, as shown in Figure $6 \mathrm{a}$ and $\mathrm{b}$. The cross section bright field TEM image in Figure $6 \mathrm{p}$ revealed a thin damaged layer of $\mathrm{GaN}$ within the first $100 \mathrm{~nm}$ of the surface, which is similar to that observed in STO and R88 (Figure 3p and Figure 4d). No amorphization or evidence of recrystallization was observed near the surface of the GaN specimen.

No dislocations were observed in the bulk of the GaN nitride specimen, except for one on the left side of Figure 6. This dislocation was likely grown-in during the crystal growth process. Of all the materials investigated here, the GaN specimen exhibited the most defect-free state after laser ablation - that is, dislocations, amorphization, crystal rotation, and evidence of recrystallization was not observed anywhere in the TEM lamella investigated.

\subsection{Post-FIB Milling Analysis}

Because all of the materials investigated here exhibited LIPSS and a high dislocation density or amorphization within the first $100 \mathrm{~nm}$ of the laser irradiated surface (STO, R88, Si, $\mathrm{GaN}$ ), an attempt was made to remove this surface damage in situ with a FIB scan after laser ablation to explore whether the combination of both techniques could provide for material surfaces with further reduced damage. FIB conditions, given in Table 2, were chosen to remove the LIPSS structures in each material, reducing the surface roughness and also the regions that typically contained the highest damage (dislocation density, amorphization). The FIB-cleaned surfaces of the STO, R88, and Si specimens are shown in Figure 7. The material removal rate of the laser is 5-6 orders of magnitude faster than that of $\mathrm{a} \mathrm{Ga}^{+}$FIB [12], thus confining material removal to a depth of only $\sim 100 \mathrm{~nm}$ and still enabling large-scale material removal in periods of time ranging from a few minutes down to a fraction of a minute.

Nearly all of the LIPSS were removed from the STO specimen after the FIB milling step, as shown in Figure 3 a, with only the dislocations remaining in the bulk of the material in the only grain oriented for easy-glide of dislocations. In the R88 specimen, the LIPSS were completely removed from the surface, as shown in Figure 7p, along with the high dislocation density present within the first $100 \mathrm{~nm}$ of the laser irradiated surface. Similarly, the LIPSS and the a-Si layer were removed via the FIB milling process in the Si specimen, as shown in Figure 5 .

SEM images were collected from regions where the sample surface was only laser ablated and regions which were subsequently $\mathrm{Ga}^{+}$FIB milled at near glancing angle $\left(<10^{\circ}\right)$. These regions of the samples were mapped using EBSD, a surface sensitive electron backscatter technique, to measure the crystallographic orientations and the diffraction band intensities. The orientations shown via IPF maps and image quality maps, which provides a measure of crystalline quality [49], are shown in Figure 8 for R88, GaN, and STO. The image quality (IQ) metric shows improvement with subsequent milling of the femtosecond laser surface in all cases except for $\mathrm{GaN}$, where the average IQ decreases, indicating that the laser ablated surface may be less damaged, or be damaged differently, than the surface that is subsequently $\mathrm{Ga}^{+}$FIB milled at near-glancing angle.

All laser ablated sample surfaces, without subsequent FIB milling, could be characterized using EBSD mapping for the crystal orientations over the entire laser machined area. However, EBSD analysis of the FIB-milled STO and R88 specimens revealed dramatically improved image quality maps over the laser only processed maps, which highlights the effectiveness of FIB milling for the reduction of surface damage imparted during the laser ablation process.

\section{Discussion}

In all the investigated materials, some form of surface structuring, dislocation injection, or phase change was present due to the femtosecond laser ablation process. LIPSS were observed in all laser irradiated materials with wavelengths ranging from $0.32 \mu \mathrm{m}$ to $0.40 \mu \mathrm{m}$ for all materials. Si exhibited amorphization extending 30-50 nm below the surface. A high density of dislocations was observed within $100 \mathrm{~nm}$ of the surface in STO and R88. Infrequently, the R88 specimen also exhibited evidence of small, recrystallized grains $(\sim 150 \mathrm{~nm}$ diameter $)$ near the peaks of the LIPSS structures at the specimen surface. Dislocations extended into the bulk in STO to a depth of $1.5 \mu \mathrm{m}$ or less in soft crystallographic orientations and as deep as $5 \mu \mathrm{m}$ in $\mathrm{Cu}$ crystals, where recrystallization was also observed. The most resilient material, in terms of damage, was GaN, which did not contain any discernible dislocations, amorphization, or recrystallization near the surface or in the bulk.

The prevalence of dislocations at the surface of STO indicates that dislocation nucleation is easily achieved and not a limiting step during femtosecond laser irradiation in the near surface region. This is likely due to the thermo-mechanical loading present as material ablates off, creating favorable dislocation nucleation conditions. Dislocation nucleation is possible in STO despite a relatively high energy required to do so in STO, compared to $\mathrm{Cu}$ or R88. It is peculiar that higher dislocation densities are not observed near the surface in $\mathrm{Si}$ or $\mathrm{GaN}$. Instead, a thin amorphized layer forms in $\mathrm{Si}$, which has also been observed elsewhere during femtosecond laser ablation [2, 25, 27, 31]. This is apparently due to the fact that the 
local combination of stress and temperature do not rise to levels required for nucleation and glide of dislocations. In $\mathrm{GaN}$, a damaged layer is formed near the surface, as shown in Figure 6p, but the TEM bright field contrast is not the same as the dislocation contrast in $\mathrm{Cu}, \mathrm{STO}$, or R88.

The prevalence of dislocations in $\mathrm{Cu}, \mathrm{STO}$, and $\mathrm{R} 88$ and the lack of dislocations in $\mathrm{Si}$ and $\mathrm{GaN}$ suggests that damage accrued during femtosecond laser irradiation strongly depends on the CRSS of the material. The CRSS of Si and GaN are one to two orders of magnitude higher than $\mathrm{Cu}$, STO, and R88. For example, at the moderate temperatures of $25-480^{\circ} \mathrm{C}$, which is in the vicinity of that expected just below the surface during ablation, the CRSS for GaN is 1-4 GPa [50]. At ambient temperature R88 has a CRSS of $402 \mathrm{MPa}$ [51], STO is $60 \mathrm{MPa}$ [45], and $\mathrm{Cu}$ is $0.63 \mathrm{MPa}$ [52]. The enhanced CRSS and lattice friction in $\mathrm{GaN}$ would inhibit dislocation motion during the femtosecond laser ablation process and results in less damage in the near surface region because the dislocations, if nucleated, are not able to glide into the material.

For glancing incidence near-threshold laser ablation, the resulting sub-surface material immediately beneath the LIPSS structures is the product of the relaxation from the highly excited plasma-like state. This final laser ablated surface is the result of near ablation threshold pulses, which result when ablating samples in the beam parallel to the surface configuration using femtosecond laser pulses that have a Gaussian beam distribution, as shown in Figure 1. The physics of the surface processes that occur as a result of the ablation process remain incompletely understood. The material remaining at the surface experiences extreme thermal and mechanical loads [14, 15, 53] providing many pathways for restructuring, generation of point defects, dislocations, or amorphization. Near the ablation threshold of silicon, the mode of relaxation is amorphization, as seen during indentation [54-56], vapor deposition [57, 58], and shock loading [59, 60]. However, neither amorphization nor dislocation generation occurred in $\mathrm{GaN}$ for laser pulses near the ablation threshold. This result suggests that bulk $\mathrm{GaN}$ relaxes back into a crystal with some elevated defect density, which may largely be point defects rather than dislocation line defects. In all other investigated materials, the immediate sub-surface layer does contain many dislocations or other defects.

The process of volumetric expansion and contraction during the cooling from the highly excited state generates shockwaves that have sufficiently low pressure to remain elastic and not plastic [14, 15, 53] at depths below 100-200 nm from the surface. The transition between an elastic and plastic wave is typically defined in the shock literature by the Hugoniot Elastic Limit (HEL) [61], or where there is a transition from an elastic wave, which can move existing defects such as dislocations to a plastic wave, where massive changes in structure such as phase transformations occur at the wave front [62, 63]. Dislocation motion has been observed in shocks below the HEL [64-66], however bulk plastic deformation is typically not observed. Plastic shockwaves require higher peak intensities that are likely to be generated at high fluences with surface-normal laser pulses [21, 22, 43, 67, 68]. The near ablation threshold fluence femtoseond laser pulses generate elastic shockwaves resulting from beam-parallel to the surface laser ablation are shown to move defects nucleated at the surface during the ablation process into the depth in STO, Cu, and the R88 alloy.

In silicon, the elastic wave may move the amorphouscrystalline interface some distance, however this is certainly a highly energetic process that does not reach beyond $100 \mathrm{~nm}$ below the surface. Other recent research shows that shock loading induced amorphization in $\mathrm{Si}$ is dependent on both high pressure and shear stresses, which can drive the amorphous interface to depths of $100 \mathrm{~nm}$ to $1 \mu \mathrm{m}$ for pressures ranging between 11 $\mathrm{GPa}$ to $22 \mathrm{GPa}$ [59, 60]. Furthermore, at $4 \mathrm{GPa}$ completely elastic material response was observed with no defect generation or phase transformation. Considering that femtosecond laser induced shockwaves in metals have peak pressures limited to the single GPa-range [14, 15, 53], the amorphous region is both expected and experimentally observed in the current study to have thickness less than $100 \mathrm{~nm}$.

For GaN, any defects that may have been generated (but were not directly observed) do not appear to be mobile and therefore remain close to the surface. The damaged region in $\mathrm{GaN}$ is confined to a 50-100 nm subsurface zone where contrast can be observed in the high-resolution TEM images in Figure 60. Furthermore, EBSD maps shows crystallinity in the near surface regions of the laser ablated GaN specimens. Indeed, with subsequent $\mathrm{Ga}^{+}$FIB near-glancing angle surface milling the EBSD image quality is somewhat diminished and therefore the damage zone is likely limited to less than that of the $30 \mathrm{kV}$ FIB operation.

In STO and the metals, dislocations were generated, which in principle are mobile and can move with the elastic wave, provided that the stresses are high enough and the defects can move at velocities near that of the speed of sound before the wave is attenuated. The CRSS of the material is a good estimate of the magnitude of the stresses required to move dislocations. Dislocation mobility is more challenging to estimate. However, any obstacles to dislocation motion that also increase the CRSS will also reduce dislocation mobility, such as the $\gamma^{\prime}$ precipitate phase that strengthens the R88 alloy. Therefore, it is expected that a strong correlation exists between the depth of the laser damage zone with the CRSS, as is apparent across the set of materials investigated in Section 3 .

Considering dislocation damage depths, dislocation velocities have been demonstrated to approach the speed of sound in pure metals such as copper [69-71]. Exact predictions of dislocation damage depth require a better understanding of the timescale of the decay in pressure as the shockwave travels into the depth of the material [14, 15, 53]. Interestingly, the dislocation mobility is extremely anisotropic in STO. While high temperature deformation is mostly achieved by the $<100>$ type dislocations [36, 45], deformation below $600^{\circ} \mathrm{C}$ is almost exclusively due to $<110>$ type dislocations which glide when the local shear stress approaches $\sim 60 \mathrm{MPa}$. Therefore, only grains which are favorably oriented with respect to slip by $<110>$ dislocations show dislocations pushed to depths up to $1.5 \mu \mathrm{m}$ by the femtosecond laser induced shockwave, as shown in Figure 3 In contrast, in the nickel-based superalloy, dislocations are present 
near the surface, but dislocation motion is obstructed by a high densities of uniformly distributed $\gamma^{\prime}$ precipitates. Consequently, dislocations cannot glide at the velocity of the elastic wave and are therefore confined to the layer very near to the surface $(<150 \mathrm{~nm})$.

The damage induced by femtosecond laser pulses at fluences near the ablation threshold can be removed by subsequently milling the sample with other types of beams, such as $\mathrm{Ga}^{+}, \mathrm{Ar}^{+}$, or $\mathrm{Xe}^{+}$ion beams, which offer a smaller damage zone or different type of final surface structure. However, these beam technologies with lower damage have significantly slower milling rates that limit the depth or volume that can be milled in a reasonable time, compared to the femtosecond laser. A small damage layer thickness is important for surface sensitive analytical techniques such as backscattered secondary electron (BSE) imaging and electron backscatter diffraction (EBSD) which can sample from depths below the surface of less than $100 \mathrm{~nm}$ [72]. In this research, the LIPSS structures and near surface dislocations or amorphization zones of 100-200nm thickness were removed by $\mathrm{Ga}^{+}$FIB milling, eliminating the primary regions of damage. However, for metals such as annealed copper with very low CRSS, regions with lower dislocation densities may still be present even after FIB milling. FIB milling also produces a damaged region, which has been shown to be as thin as $5-10 \mathrm{~nm}$ in $\mathrm{Si}$ at low $\mathrm{kV}$ and up to $20-30 \mathrm{~nm}$ for higher $\mathrm{kVs}$ [73]. For laser machined surface areas approaching $\mathrm{mm}^{2}, \mathrm{Ga}^{+}$ FIB milling to depths of $>2 \mu \mathrm{m}$ would require 14 hours worth of milling compared to 2-3 minutes by laser machining [74, 75], rendering such operations infeasible without using a combined beam approach. In general for Gaussian shaped beams, including Fs laser and $\mathrm{Ga}^{+}$FIB, the damage is most limited in the configuration where the beam is milling parallel (or at a near glancing angle) to the sample surface.

\section{Conclusions}

The immediate subsurface region (a few $100 \mathrm{~nm}$ ) for near ablation threshold femtosecond laser irradiation in glancing incidence experiences a complicated thermo-mechanical environment, which can result in elevated dislocation densities (R88, $\mathrm{STO}, \mathrm{Cu}$ ), phase transformations (Si), or occasional recrystallization (R88), depending on the material. Further below the immediate subsurface region (a few hundred nm to micrometers), the presence of dislocations is dependent on the mechanical properties of the material being ablated. In materials with high CRSS, such as GaN, Si, R88, and some grain orientations in STO, the resolved shear stresses are not large enough to glide the dislocations nucleated near the surface during ablation into the bulk. However, for materials with low CRSS, such as $\mathrm{Cu}$ and some grain orientations in STO, dislocations nucleated near the surface during the ablation event are pushed to micrometer depths by the elastic shockwave accompanying the femtosecond laser pulse. The exception to these cases are materials that can undergo phase transformations during the thermo-mechanical interaction at the ablation event. Silicon, for instance, exhibits amorphization to depths of 30-50 nm when femtosecond laser irradiated with near ablation threshold energies. The LIPSS surface structures that form on the surface of all the materials studied have variability in both amplitude and periodicity that does not appear to be directly related to the wavelength of the irradiating laser light.

\section{Acknowledgments}

This work was supported in part by NSF IRG Grant \# (DMR 1121053), ONR Grant \# (N00014-16-1-2703), the Institute for Collborative Biotechnology Grant \# (W911NF-09-0001), and the MRL Shared Experimental Facilities, which are supported by the MRSEC Program of the NSF under Award No. DMR 1121053; a member of the NSF-funded Materials Research Facilities Network (www.mrfn.org). We also thank Stephan Krämer for his useful discussion on silicon amorphization and Erin Young for the GaN samples. 
Table 1: Measurements of the light induced periodic surface structures (LIPSS) by SEM and TEM that result from femtosecond laser machining are given for the materials investigated.

\begin{tabular}{|c|c|c|}
\hline Material & Wavelength (SEM) $[\mathrm{nm}]$ & Amplitude (TEM) $[\mathrm{nm}]$ \\
\hline $\mathrm{Cu}$ & $342 \pm 55$ & $323 \pm 102$ \\
$\mathrm{SrTiO}_{3}$ & $400 \pm 50$ & $74 \pm 45$ \\
René 88DT & $337 \pm 58$ & $222 \pm 72$ \\
$\mathrm{Si}$ & $363 \pm 64$ & $55 \pm 16$ \\
$\mathrm{GaN}$ & $320 \pm 28$ & $177 \pm 87$ \\
\hline
\end{tabular}

Table 2: Focused ion beam accelerating voltage $\left(\mathrm{A}_{v}\right)$ and beam current (I) used to mill at near glancing angle of $10^{\circ}$ off parallel to the surface of strontium titanate, silicon, and polycrystalline nickel alloy sample. Ion milling was performed in a selected area inset within the laser ablated surface region to compare the sub-surface damage structure between the femtosecond laser + ion milling and femtosecond laser only.

\begin{tabular}{|c|c|c|}
\hline & $\mathrm{A}_{v}(\mathrm{kV})$ & $\mathrm{I}(\mathrm{nA})$ \\
\hline $\mathrm{SrTiO}_{3}$ & 30 and 5 & 30 and 13 \\
\hline $\mathrm{R} 88$ & 30 & 20 \\
\hline $\mathrm{Si}$ & 8 & 20 \\
\hline
\end{tabular}
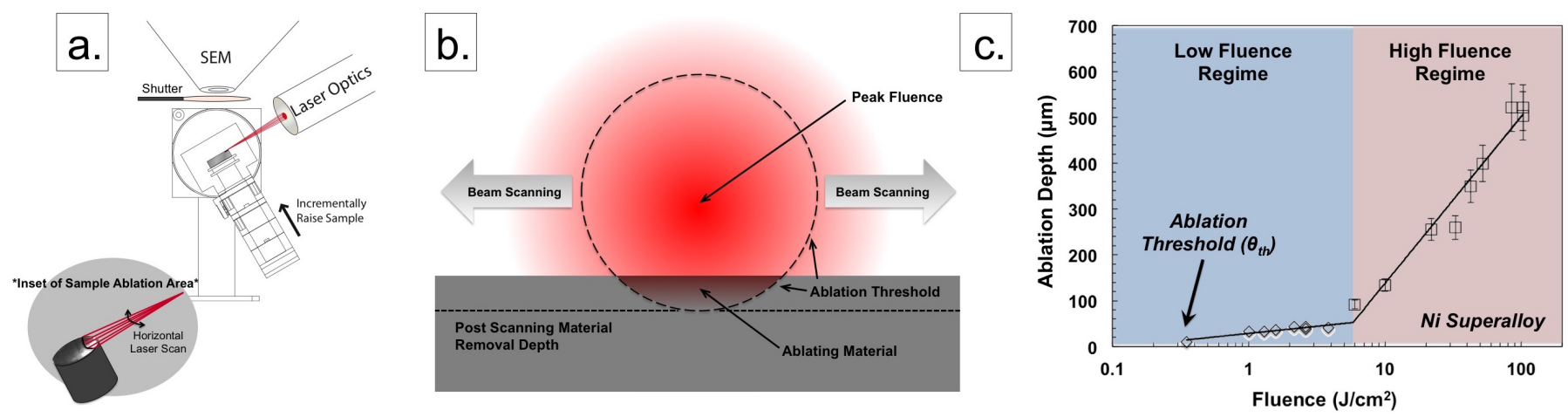

Figure 1: A schematic of the chamber section of the TriBeam system [11,34], in (a), shows the position of the piezoelectric driven stages which permit in situ laser ablation. The laser beam propagation direction is parallel with the sample surfaces and is scanned laterally over mm-scale areas using a $<2 \mu$-radian resolution laser scanner as shown in the inset in (a). The laser optics used in this experiment focus the beam to a $29 \mu \mathrm{m}$ FWHM diameter spot with a depth of focus of $0.98 \mathrm{~mm}$. The laser beam energy distribution is shown in (b), with relation to the sample surface being irradiated as viewed down the beam propagation direction. The beam is scanned as indicated and material from the sample located at the edge of the beam profile, above the ablation threshold is removed. As the sample is incrementally raised into the beam using the piezo stage z-positioner then ablation will be confined to the sub-surface region that is equal to the increment size. Furthermore, the tail of the Gaussian beam profile is the only part of the beam interacting with the sample surface, with fluences at or very near the ablation threshold of the sample material. The ablation threshold and ablation depth for single pulses laser irradiated with beam-normal to the sample surface incidence, which scale with the radial position in the Gaussian beam profile, are shown in (c) for a nickel base superalloy (after Ma et al [20]). 

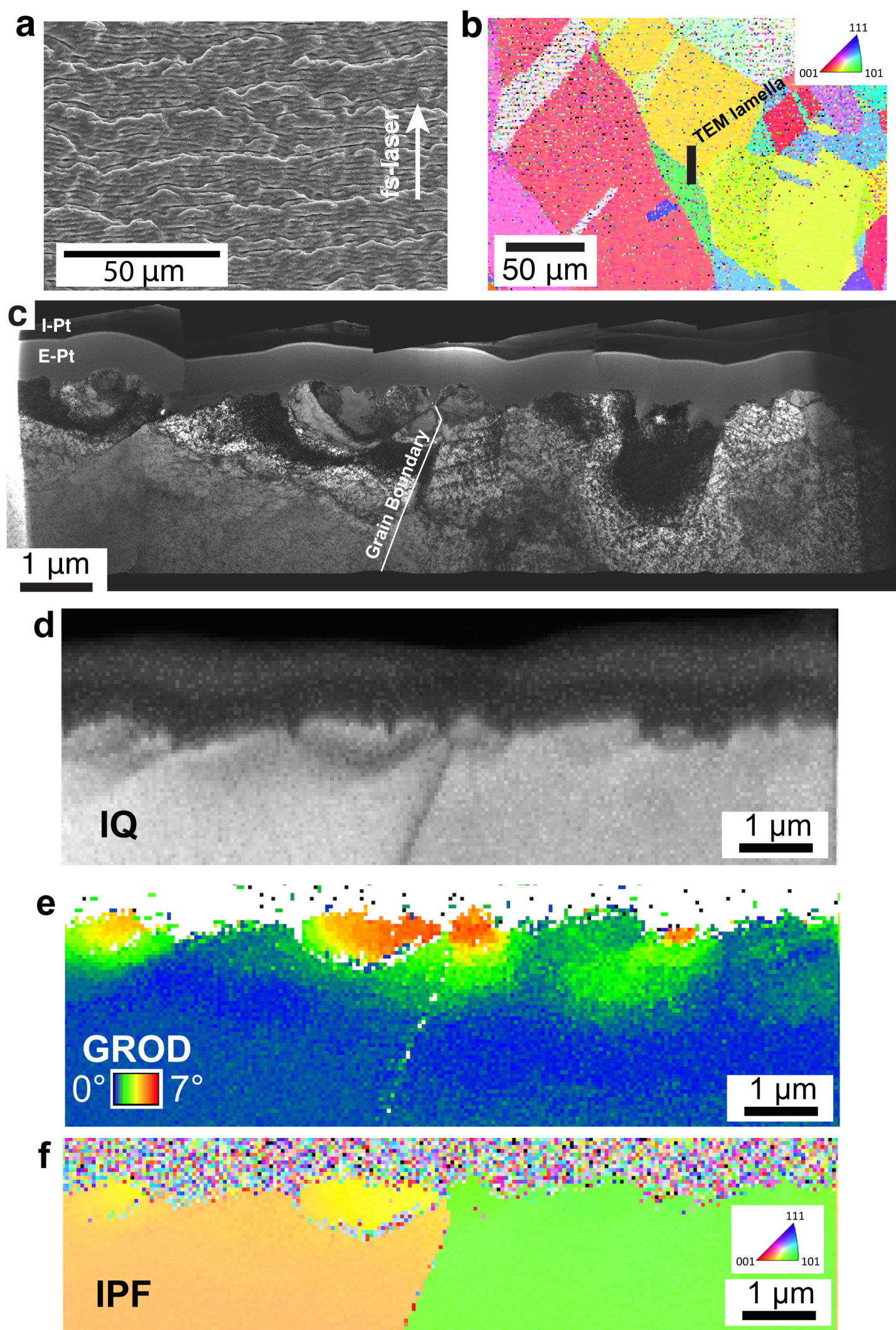

Figure 2: SEM micrograph of the the laser irradiated Cu specimen surface in (a) with the an overview EBSD inverse pole figure (IPF) map shown in (b). The TEM lamella liftout location is shown in (b), and the cross section is shown in bright-field TEM mode near a zone axis in (c). A grain boundary is highlighted in red. Lattice rotations of roughly $1^{\circ}$ can be observed in the TEM cross section (c). EBSD maps collected from the TEM lamella are represented by image quality (IQ) (d) and IPF (f). Misorientation gradients of $4-7^{\circ}$, particularly in regions near the surface shown in the grain reference orientation deviation plot (e). 

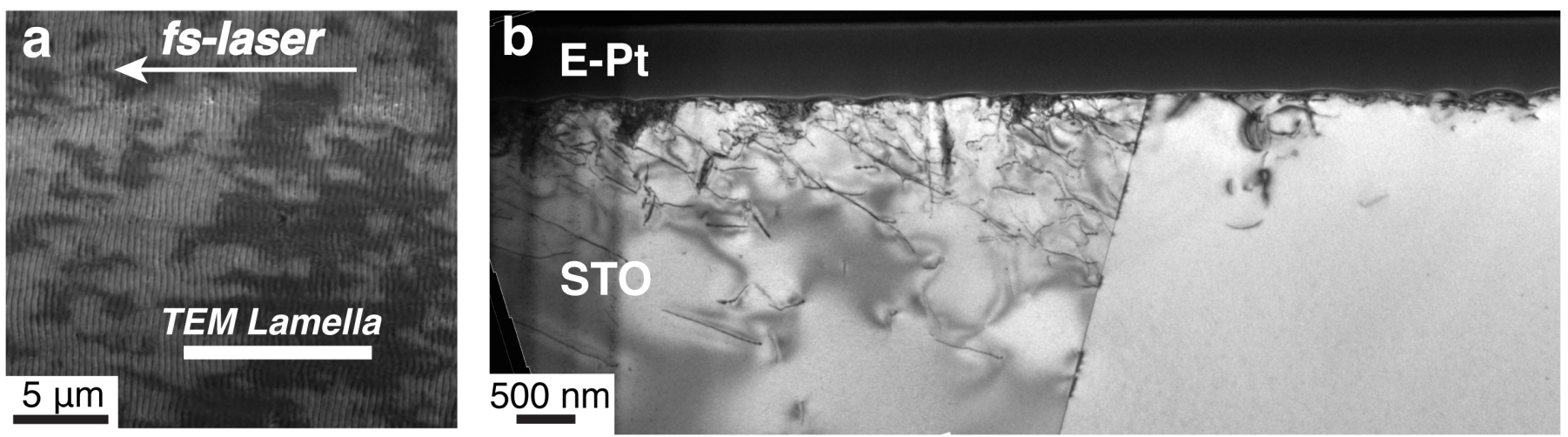

Figure 3: A SEM micrograph of the STO specimen of the laser irradiated surface with the corresponding TEM lamella liftout location is shown in (a). The TEM cross section imaged in bright field mode, shown in (b), reveals a high dislocation density near the surface with dislocations penetrating up to $1.5 \mu \mathrm{m}$ below the ablated surface, into the bulk in a soft oriented STO grain.
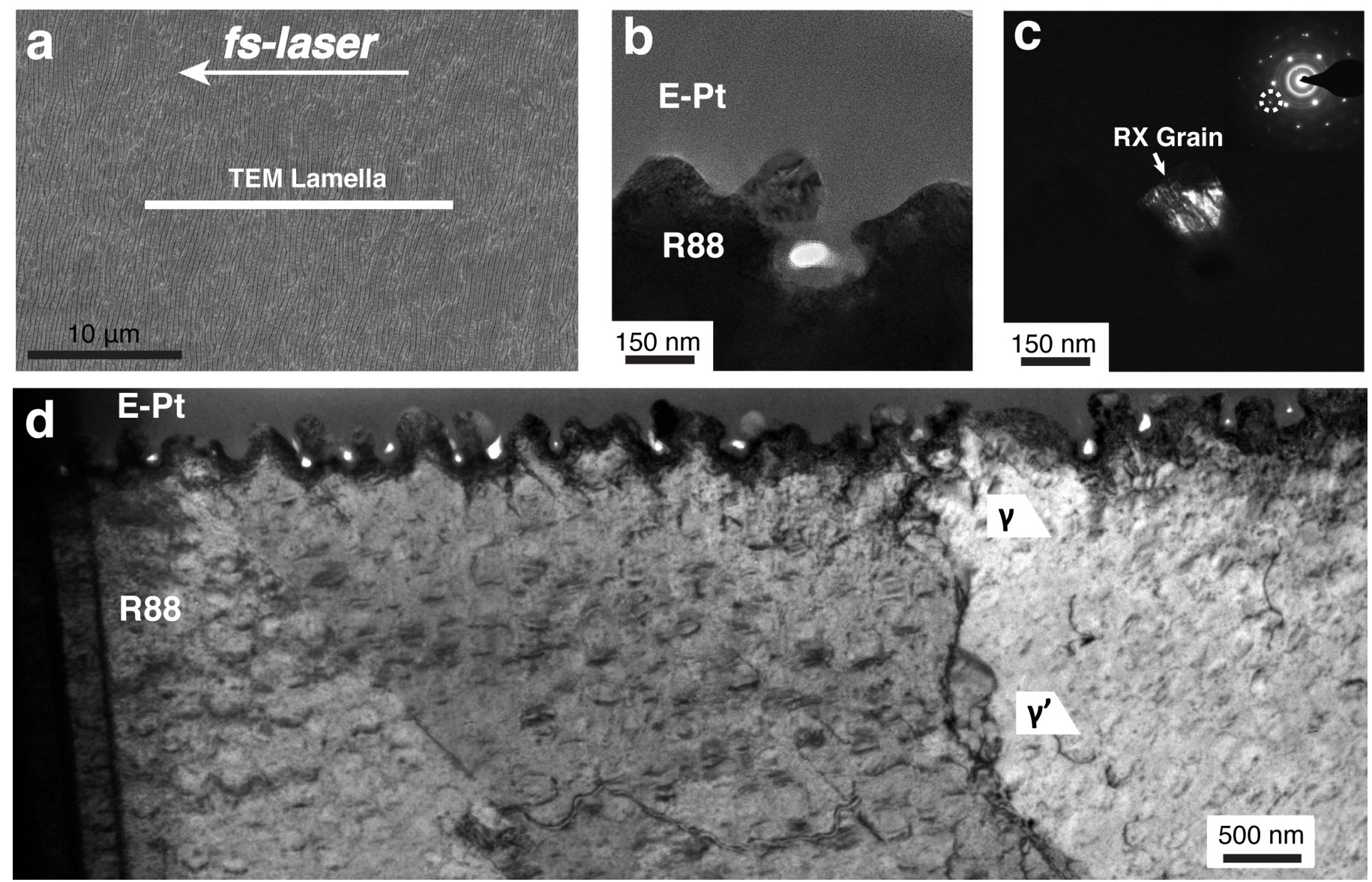

Figure 4: A SEM micrograph of the laser irradiated surface of a R88 specimen is shown in (a) with the corresponding location of the TEM lamella liftout. A high density of dislocations is present in the subsurface $100-200 \mathrm{~nm}$ and evidence of recrystallization was observed, as shown in the bright field image in (b) and corresponding dark field image in (c) using the reflection circled in the diffraction pattern inset. Recrystallized regions of less than 150 nm in size are observed 1-2 times per $10 \mu \mathrm{m}$ lamella. The entire TEM cross section is shown under bright field conditions in (d). Some dislocations can be observed in the bulk of the specimen, however due to their low density, these are regarded as grown-in dislocations as a result of the material processing. 

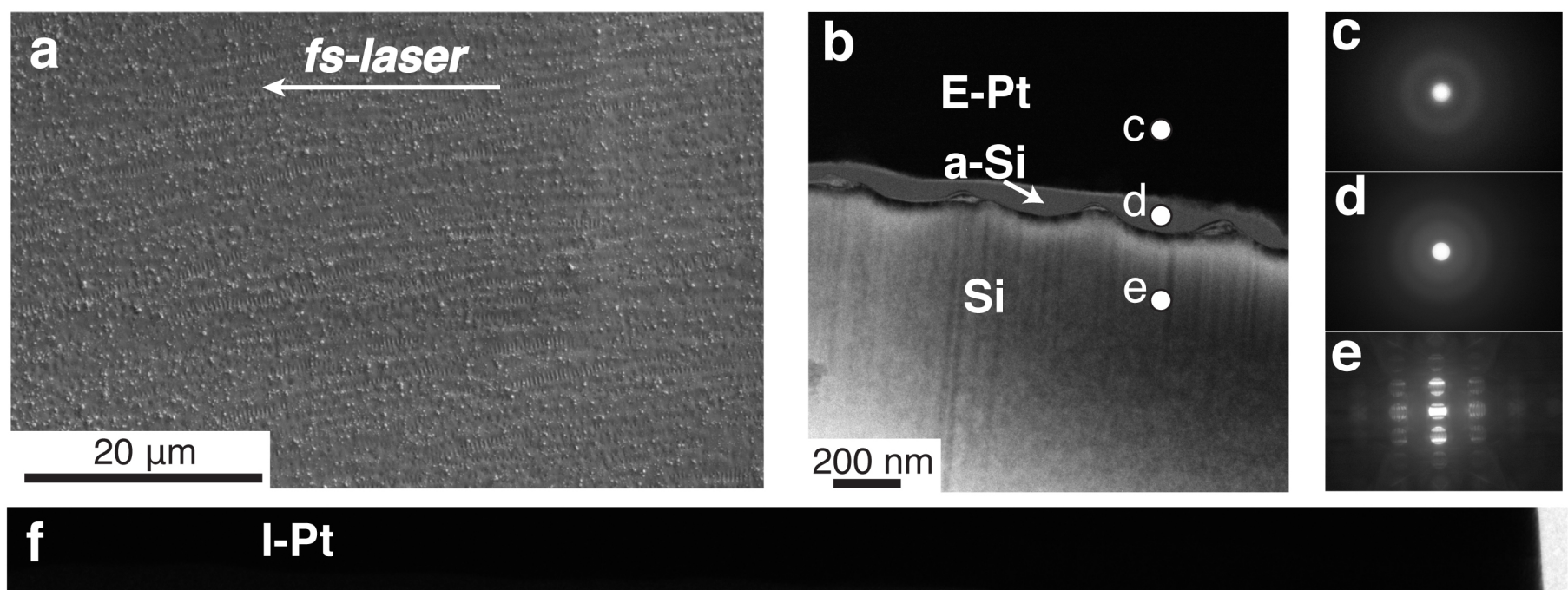

\section{E-Pt}

$$
\text { a-Și }
$$

\section{Si}

\section{$0.5 \mu \mathrm{m}$}

Figure 5: A SEM overview of the laser irradiated Si surface is shown in (a). A thin amorphized Si layer was observed at the surface extending 30-50nm in depth (b), with the corresponding CBED patterns in (c-e). The entire TEM cross section is shown in bright field mode in (f). No dislocations or damage, other than the near sub-surface amorphized layer, was observed. 

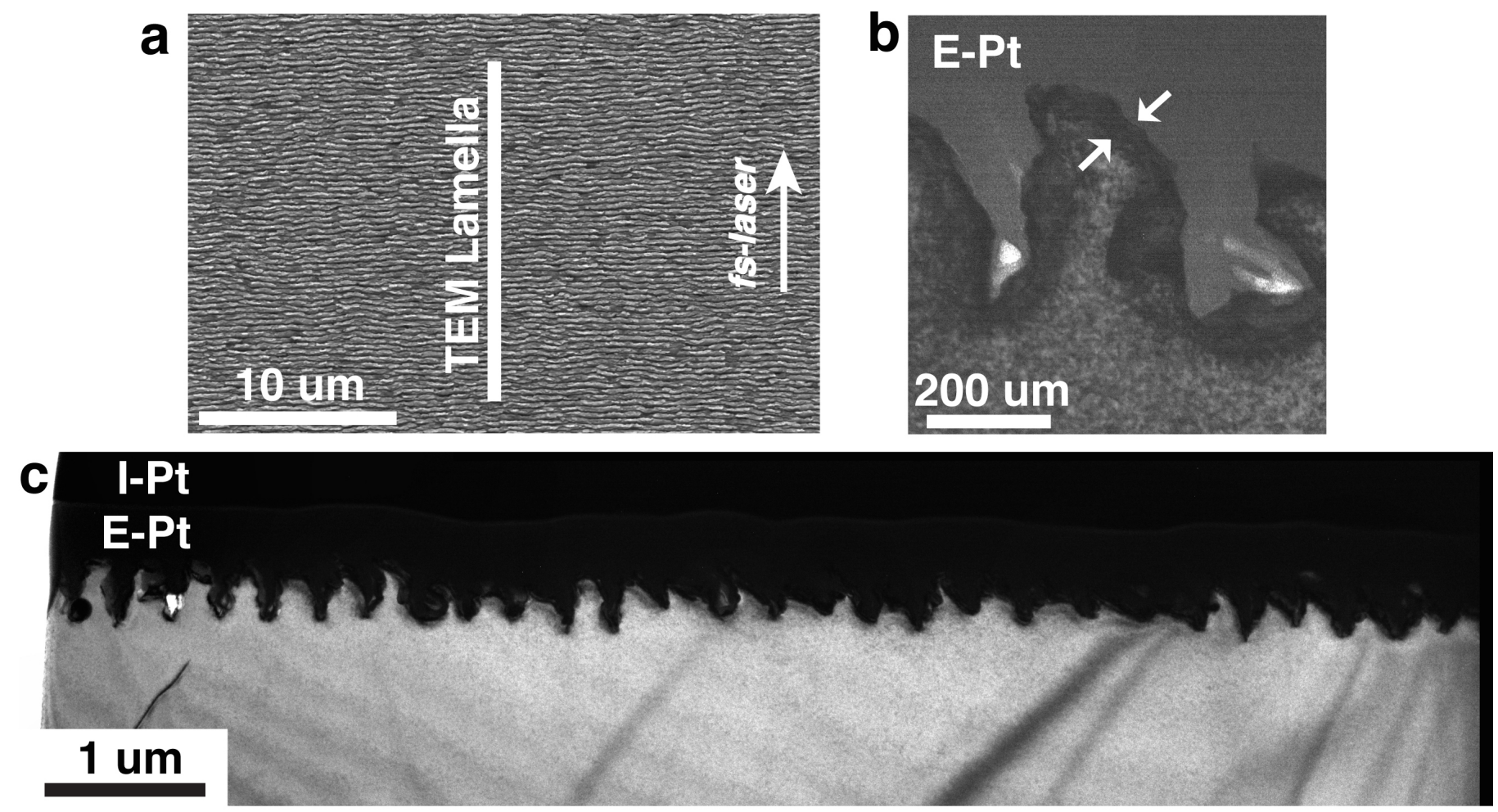

Figure 6: A SEM micrograph of the GaN specimen post laser irradiation is shown in (a). Limited damage was observed near the surface, as shown between the arrows in the cross section TEM micrograph in (b), but the contrast suggests that dislocations were not present. The full TEM cross section is shown in (c) under bright field conditions. No dislocations were observed in the bulk, except for the grown-in dislocation near the left side of the micrograph. 

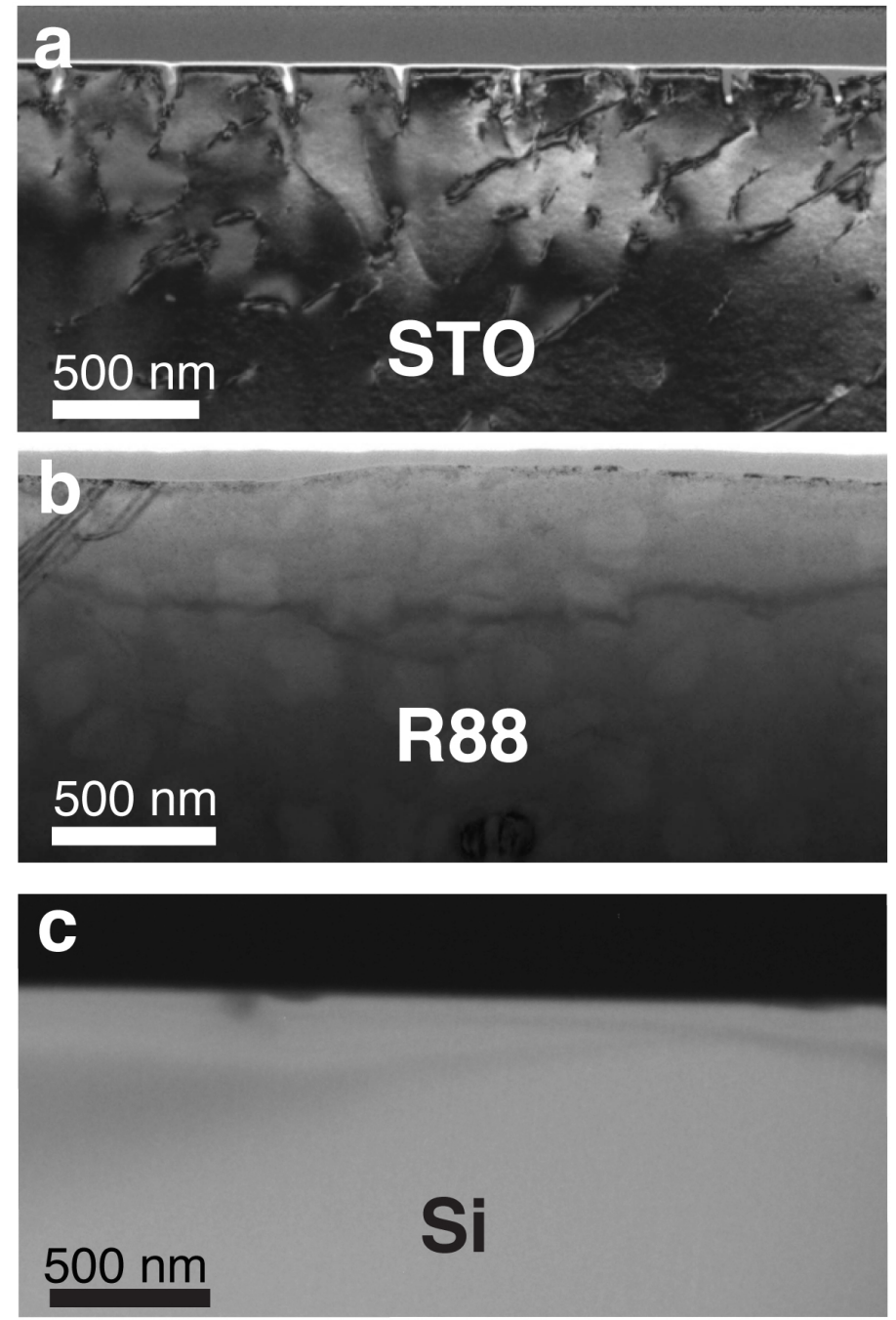

Figure 7: TEM cross sections of the laser and FIB processed surfaces are shown for (a) STO, (b) R88, and (c) Si. The LIPSS structures were removed by the near glancing angle $\left(<10^{\circ}\right) \mathrm{FIB}$ processing as well as the amorphized layer in $\mathrm{Si}$. 

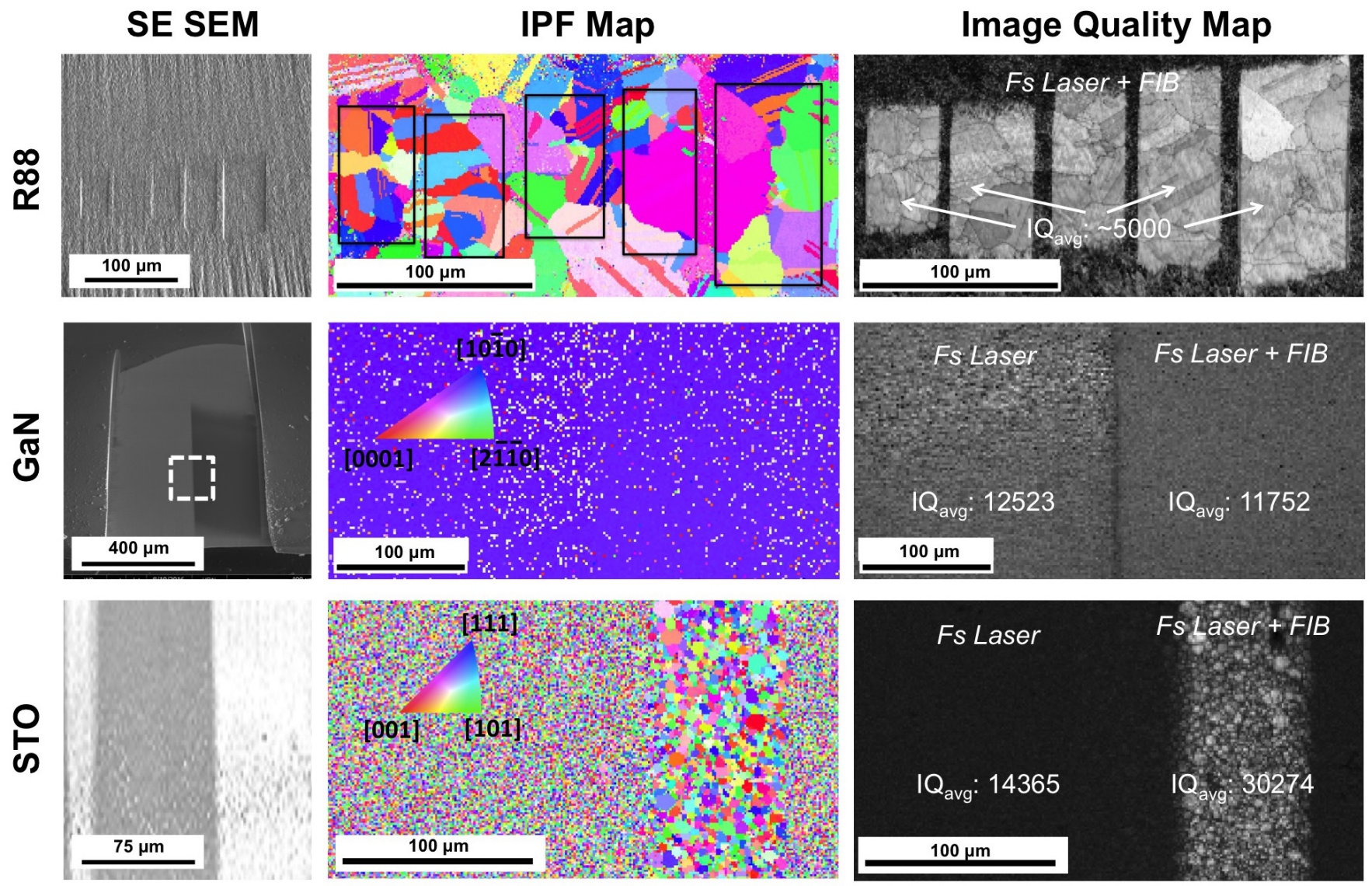

Figure 8: Femtosecond laser ablated surfaces of R88, GaN, and STO were mapped using EBSD, a electron diffraction based technique with a 10-100 nm scaled subsurface interaction depth. Secondary electron images show the femtosecond laser ablated regions and the subregions that were $\mathrm{Ga}^{+} \mathrm{FIB}_{\mathrm{Billed}}$ with a $>10^{\circ}$ near-glancing angle beam. The inverse pole figure (IPF) maps show the crystallographic orientations indexed using the EBSD software from the sample surfaces. The image quality maps show the enhanced electron beam diffraction within the regions that were FIB milled after femtosecond laser ablation, however for GaN and R88 the sample surface can be indexed without the subsequent FIB milling step. 
[1] R. R. Gattass, E. Mazur, Femtosecond laser micromachining in transparent materials, Nat Photon 2 (2008) 219-225.

[2] J. Bonse, S. Baudach, J. Krüger, W. Kautek, M. Lenzner, Femtosecond laser ablation of silicon-modification thresholds and morphology, Applied Physics A 74 (2002) 19-25.

[3] A. Borowiec, M. MacKenzie, G. C. Weatherly, H. K. Haugen, Femtosecond laser pulse ablation of gaas and inp: studies utilizing scanning and transmission electron microscopy, Applied Physics A 77 (2003) 411417.

[4] B. Chichkov, C. Momma, S. Nolte, F. von Alvensleben, A. Tünnermann, Femtosecond, picosecond and nanosecond laser ablation of solids, Applied Physics A 63 (1996) 109-115.

[5] Q. Feng, Y. Picard, H. Liu, S. Yalisove, G. Mourou, T. Pollock, Femtosecond laser micromachining of a single-crystal superalloy, Scripta Materialia 53 (2005) $511-516$

[6] K. Furusawa, K. Takahashi, H. Kumagai, K. Midorikawa, M. Obara, Ablation characteristics of au, ag, and cu metals using a femtosecond ti:sapphire laser, Applied Physics A 69 (1999) S359-S366.

[7] F. Watanabe, D. G. Cahill, B. Gundrum, R. S. Averback, Ablation of crystalline oxides by infrared femtosecond laser pulses, Journal of Applied Physics 100 (2006) 083519.

[8] N. Yasumaru, K. Miyazaki, J. Kiuchi, Fluence dependence of femtosecond-laser-induced nanostructure formed on TiN and $\mathrm{CrN}$, Ap- plied Physics A: Materials Science \& Processing, 81 (2005) 933-937.

[9] J. P. McDonald, D. K. Das, J. A. Nees, T. M. Pollock, S. M. Yalisove, Approaching non-destructive surface chemical analysis of cmsx-4 superalloy with double-pulsed laser induced breakdown spectroscopy, Spectrochimica Acta Part B: Atomic Spectroscopy 63 (2008) 561 - 565.

[10] D. K. Das, J. P. McDonald, C. G. Levi, S. M. Yalisove, T. M. Pollock, Detection of a marker layer in a 7ysz thermal barrier coating by femtosecond laser-induced breakdown spectroscopy, Surface and Coatings Technology 202 (2008) 3940 - 3946.

[11] M. P. Echlin, A. Mottura, C. Torbet, T. M. Pollock, A new TriBeam system for three-dimensional multimodal analysis, Review of Scientific Instruments 83 (2012) 023701.

[12] M. P. Echlin, M. Straw, S. Randolph, J. Filevich, T. M. Pollock, The tribeam system: Femtosecond laser ablation in situ $\{$ SEM\}, Materials Characterization 100 (2015) $1-12$.

[13] B. Rethfeld, K. Sokolowski-Tinten, D. von der Linde, S. Anisimov, Timescales in the response of materials to femtosecond laser excitation, Applied Physics A-Materials Science \& Processing 79 (2004) 767-769.

[14] B. J. Demaske, V. V. Zhakhovsky, N. A. Inogamov, I. I. Oleynik, Ablation and spallation of gold films irradiated by ultrashort laser pulses, Phys. Rev. B 82 (2010) 064113.

[15] C. Wu, M. S. Christensen, J.-M. Savolainen, P. Balling, L. V. Zhigilei, Generation of subsurface voids and a nanocrystalline surface layer in femtosecond laser irradiation of a single-crystal ag target, Physical Review B 91 (2015).

[16] A.-C. Tien, S. Backus, H. Kapteyn, M. Murnane, G. Mourou, Shortpulse laser damage in transparent materials as a function of pulse duration, Phys. Rev. Lett. 82 (1999) 3883-3886.

[17] R. Le Harzic, N. Huot, E. Audouard, C. Jonin, P. Laporte, S. Valette, A. Fraczkiewicz, R. Fortunier, Comparison of heat-affected zones due to nanosecond and femtosecond laser pulses using transmission electronic microscopy, Applied Physics Letters 80 (2002) 3886-3888.

[18] P. T. Mannion, J. Magee, E. Coyne, G. M. O'Connor, T. J. Glynn, The effect of damage accumulation behaviour on ablation thresholds and damage morphology in ultrafast laser micro-machining of common metals in air, Applied Surface Science 233 (2004) 275-287.

[19] S. Nolte, C. Momma, H. Jacobs, A. Tünnermann, B. N. Chichkov, B. Wellegehausen, H. Welling, Ablation of metals by ultrashort laser pulses, J. Opt. Soc. Am. B 14 (1997) 2716-2722.

[20] S. Ma, J. McDonald, B. Tryon, S. Yalisove, T. Pollock, Femtosecond laser ablation regimes in a single-crystal superalloy, Metallurgical and Materials Transactions A 38 (2007) 2349-2357.

[21] A. Kumar, T. Pollock, Mapping of femtosecond laser-induced collateral damage by electron backscatter diffraction, Journal of Applied Physics 110 (2011) 083114.

[22] X. Sedao, C. Maurice, F. Garrelie, J.-P. Colombier, S. Reynaud, R. Quey, G. Blanc, F. Pigeon, Electron backscatter diffraction characterization of laser-induced periodic surface structures on nickel surface, Applied Surface Science 302 (2014) 114 - 117. E-MRS 2013 Symposium V: "Laser Material Interactions for Micro- and Nano- Applications" 27-31 May 2013, Strasbourg (France).

[23] Y. N. Picard, S. M. Yalisove, Femtosecond laser heat affected zones profiled in cosi multilayer thin films, Applied Physics Letters 92 (2008) 014102 .

[24] S. Valette, E. Audouard, R. L. Harzic, N. Huot, P. Laporte, R. Fortunier, Heat affected zone in aluminum single crystals submitted to femtosecond laser irradiations, Applied Surface Science 239 (2005) 381 - 386.

[25] J. Bonse, K.-W. Brzezinka, A. Meixner, Modifying single-crystalline silicon by femtosecond laser pulses: an analysis by micro raman spectroscopy, scanning laser microscopy and atomic force microscopy, Applied Surface Science 221 (2004) 215 - 230.

[26] F. Costache, S. Kouteva-Arguirova, J. Reif, Sub-damage-threshold femtosecond laser ablation from crystalline si: surface nanostructures and phase transformation, Applied Physics A 79 (2004) 1429-1432.

[27] T. H. R. Crawford, J. Yamanaka, G. A. Botton, H. K. Haugen, Highresolution observations of an amorphous layer and subsurface damage formed by femtosecond laser irradiation of silicon, Journal of Applied Physics 103 (2008) 053104

[28] J. Ihlemann, A. Scholl, H. Schmidt, B. Wolff-Rottke, Nanosecond and femtosecond excimer-laser ablation of oxide ceramics, Applied Physics A 60 (1995) 411-417. 
[29] J. P. McDonald, S. Ma, T. M. Pollock, S. M. Yalisove, J. A. Nees, Femtosecond pulsed laser ablation dynamics and ablation morphology of nickel based superalloy cmsx-4, Journal of Applied Physics 103 (2008) 093111.

[30] T. Sarnet, J. E. Carey, E. Mazur, From black silicon to photovoltaic cells, using short pulse lasers, AIP Conference Proceedings 1464 (2012) 219_ 228.

[31] E. Coyne, J. Magee, P. Mannion, G. O'Connor, T. Glynn, Stem (scanning transmission electron microscopy) analysis of femtosecond laser pulse induced damage to bulk silicon, Applied Physics A 81 (2005) 371-378.

[32] T. Gorelik, M. Will, S. Nolte, A. Tuennermann, U. Glatzel, Transmission electron microscopy studies of femtosecond laser induced modifications in quartz, Applied Physics A 76 (2003) 309-311.

[33] A. Borowiec, M. MacKenzie, G. Weatherly, H. Haugen, Transmission and scanning electron microscopy studies of single femtosecond- laserpulse ablation of silicon, Applied Physics A: Materials Science \& Processing 76 (2003) 201-207.

[34] M. P. Echlin, A. Mottura, M. Wang, P. J. Mignone, D. P. Riley, G. V. Franks, T. M. Pollock, Three-dimensional characterization of the permeability of w-cu composites using a new "tribeam"technique, Acta Materialia 64 (2014) 307-315.

[35] P. Pronko, S. Dutta, D. Du, R. Singh, Thermophysical effects in laser processing of materials with picosecond and femtosecond pulses, Journal of applied physics 78 (1995) 6233-6240.

[36] M. S. Titus, M. P. Echlin, P. Gumbsch, T. M. Pollock, Dislocation injection in strontium titanate by femtosecond laser pulses, Journal of Applied Physics 118 (2015) 075901.

[37] J. Bonse, J. Krüger, Pulse number dependence of laser-induced periodic surface structures for femtosecond laser irradiation of silicon, Journal of Applied Physics 108 (2010) 034903

[38] H. van Driel, J. Sipe, J. Young, Laser-induced periodic surface structure on solids: A universal phenomenon, Phys. Rev. Lett. 49 (1982) 19551958

[39] J. F. Young, J. E. Sipe, H. M. van Driel, Laser-induced periodic surface structure. iii. fluence regimes, the role of feedback, and details of the induced topography in germanium, Phys. Rev. B 30 (1984) 2001-2015.

[40] Z. Guosheng, P. Fauchet, A. Siegman, Growth of spontaneous periodic surface structures on solids during laser illumination, Physical Review B 26 (1982) 5366-5381

[41] M. Huang, F. Zhao, Y. Cheng, N. Xu, Z. Xu, Origin of laser-induced near-subwavelength ripples: Interference between surface plasmons and incident laser, ACS Nano 3 (2009) 4062-4070.

[42] A. Agnoli, M. Bernacki, R. Logé, J.-M. Franchet, J. Laigo, N. Bozzolo, Selective growth of low stored energy grains during sub-solvus annealing in the inconel 718 nickel-based superalloy, Metallurgical and Materials Transactions A 46 (2015) 4405-4421.

[43] M. S. Schneider, B. Kad, D. H. Kalantar, B. A. Remington, E. Kenik, H. Jarmakani, M. A. Meyers, Laser shock compression of copper and copper-aluminum alloys, International Journal of Impact Engineering 32 (2005) 473 - 507. Fifth International Symposium on Impact Engineering.

[44] D. Brunner, S. Taeri-Baghbadrani, W. Sigle, M. Rühle, Surprising results of a study on the plasticity in strontium titanate, Journal of the American Ceramic Society 84 (2001) 1161-1163.

[45] P. Gumbsch, S. Taeri-Baghbadrani, D. Brunner, W. Sigle, M. Rühle, Plasticity and an inverse brittle-to-ductile transition in strontium titanate, Phys. Rev. Lett. 87 (2001) 085505.

[46] S. Taeri, D. Brunner, W. Sigle, M. Rühle, Deformation behaviour of strontium titanate between room temperature and $1800 \mathrm{k}$ under ambient pressure, Zeitschrift für Metallkunde 95 (2004) 433-446.

[47] W. Sigle, C. Sarbu, D. Brunner, M. Rühle, Dislocations in plastically deformed srtio3, Philosophical Magazine 86 (2006) 4809-4821.

[48] J. Bonse, A. Rosenfeld, J. Krüger, On the role of surface plasmon polaritons in the formation of laser-induced periodic surface structures upon irradiation of silicon by femtosecond-laser pulses, Journal of Applied Physics 106 (2009) 104910.

[49] S. I. Wright, M. M. Nowell, Ebsd image quality mapping, Microscopy and Microanalysis 12 (2006) 72-84.

[50] J. Wheeler, C. Niederberger, C. Tessarek, S. Christiansen, J. Michler, Extraction of plasticity parameters of gan with high temperature, in situ micro-compression, International Journal of Plasticity 40 (2013) 140 151.
[51] E. S. Huron, Serrated yielding in a nickel-base superalloy, 1992.

[52] F. Rosi, Stress-strain characteristics and slip-band formation in metal crystals: effect of crystal orientation, AIME TRANS 200 (1954) 10091020 .

[53] B. Demaske, V. Zhakhovsky, N. Inogamov, I. Oleynik, Ultrashort shock waves in nickel induced by femtosecond laser pulses, Phys. Rev. B 87 (2013) 054109.

[54] D. R. Clarke, M. C. Kroll, P. D. Kirchner, R. F. Cook, B. J. Hockey, Amorphization and conductivity of silicon and germanium induced by indentation, Phys. Rev. Lett. 60 (1988) 2156-2159.

[55] D. L. Callahan, J. C. Morris, The extent of phase transformation in silicon hardness indentations, Journal of Materials Research 7 (1992) 16141617.

[56] J. il Jang, M. Lance, S. Wen, T. Y. Tsui, G. Pharr, Indentation-induced phase transformations in silicon: influences of load, rate and indenter angle on the transformation behavior, Acta Materialia 53 (2005) 1759 -1770 .

[57] T. Kamins, M. Mandurah, K. Saraswat, Structure and stability of low pressure chemically vapor-deposited silicon films, Journal of The Electrochemical Society 125 (1978) 927-932.

[58] M. K. Hatalis, D. W. Greve, Large grain polycrystalline silicon by lowtemperature annealing of lowpressure chemical vapor deposited amorphous silicon films, Journal of Applied Physics 63 (1988) 2260-2266.

[59] S. Zhao, B. Kad, E. Hahn, B. Remington, C. Wehrenberg, C. Huntington, H.-S. Park, E. Bringa, K. More, M. Meyers, Pressure and shear-induced amorphization of silicon, Extreme Mechanics Letters 5 (2015) $74-80$.

[60] S. Zhao, E. Hahn, B. Kad, B. Remington, C. Wehrenberg, E. Bringa, M. Meyers, Amorphization and nanocrystallization of silicon under shock compression, Acta Materialia 103 (2016) 519 - 533.

[61] J. Asay, M. Shahinpoor, High-Pressure Shock Compression of Solids, Shock Wave and High Pressure Phenomena, Springer New York, 2012. URL: https://books.google.com/books?id=kzzaBwAAQBAJ

[62] K. Kadau, T. C. Germann, P. S. Lomdahl, B. L. Holian, Microscopic view of structural phase transitions induced by shock waves, Science 296 (2002) 1681-1684.

[63] B. L. Holian, P. S. Lomdahl, Plasticity induced by shock waves in nonequilibrium molecular-dynamics simulations, Science 280 (1998) 2085-2088.

[64] L. H. L. Louro, M. A. Meyers, Effect of stress state and microstructural parameters on impact damage of alumina-based ceramics, Journal of Materials Science 24 (1989) 2516-2532.

[65] J. Lankford, W. Predebon, J. Staehler, G. Subhash, B. Pletka, C. Anderson, The role of plasticity as a limiting factor in the compressive failure of high strength ceramics, Mechanics of Materials 29 (1998) $205-218$

[66] N. K. Bourne, J. C. F. Millett, G. T. Gray, On the shock compression of polycrystalline metals, Journal of Materials Science 44 (2009) 3319 3343.

[67] M. Meyers, F. Gregori, B. Kad, M. Schneider, D. Kalantar, B. Remington, G. Ravichandran, T. Boehly, J. Wark, Laser-induced shock compression of monocrystalline copper: characterization and analysis, Acta Materialia 51 (2003) $1211-1228$.

[68] M. Schneider, B. Kad, M. Meyers, F. Gregori, D. Kalantar, B. Remington, Laser-induced shock compression of copper: Orientation and pressure decay effects, Metallurgical and Materials Transactions A 35 (2004) 2633-2646.

[69] R. W. Armstrong, W. Arnold, F. J. Zerilli, Dislocation mechanics of copper and iron in high rate deformation tests, Journal of Applied Physics 105 (2009) 023511

[70] E. Bitzek, P. Gumbsch, Atomistic study of drag, surface and inertial effects on edge dislocations in face-centered cubic metals, Materials Science and Engineering: A 387-389 (2004) 11 - 15. 13th International Conference on the Strength of Materials.

[71] E. Bitzek, P. Gumbsch, Dynamic aspects of dislocation motion: atomistic simulations, Materials Science and Engineering: A 400-401 (2005) 40 44. Dislocations 2004An International Conference on the Fundamentals of Plastic Deformation.

[72] P. G. Callahan, M. De Graef, Dynamical electron backscatter diffraction patterns. part i: Pattern simulations, Microscopy and Microanalysis 19 (2013) 1255-1265.

[73] N. I. Kato, Reducing focused ion beam damage to transmission electron microscopy samples, Journal of Electron Microscopy 53 (2004) 451-458. 
[74] L. Kwakman, M. Straw, G. Coustillier, M. Sentis, J. Beyersdorfer, J. Schischka, F. Naumann, F. Altmann, Sample preparation strategies for fast and effective failure analysis of 3d devices, in: ISTFA 2013: Proceedings from the 39th International Symposium for Testing and Failure Analysis, ASM International, 2013, p. 17.

[75] M. P. Echlin, N. S. Husseini, J. A. Nees, T. M. Pollock, A new femtosecond laser-based tomography technique for multiphase materials, Advanced Materials 23 (2011) 2339-2342. 


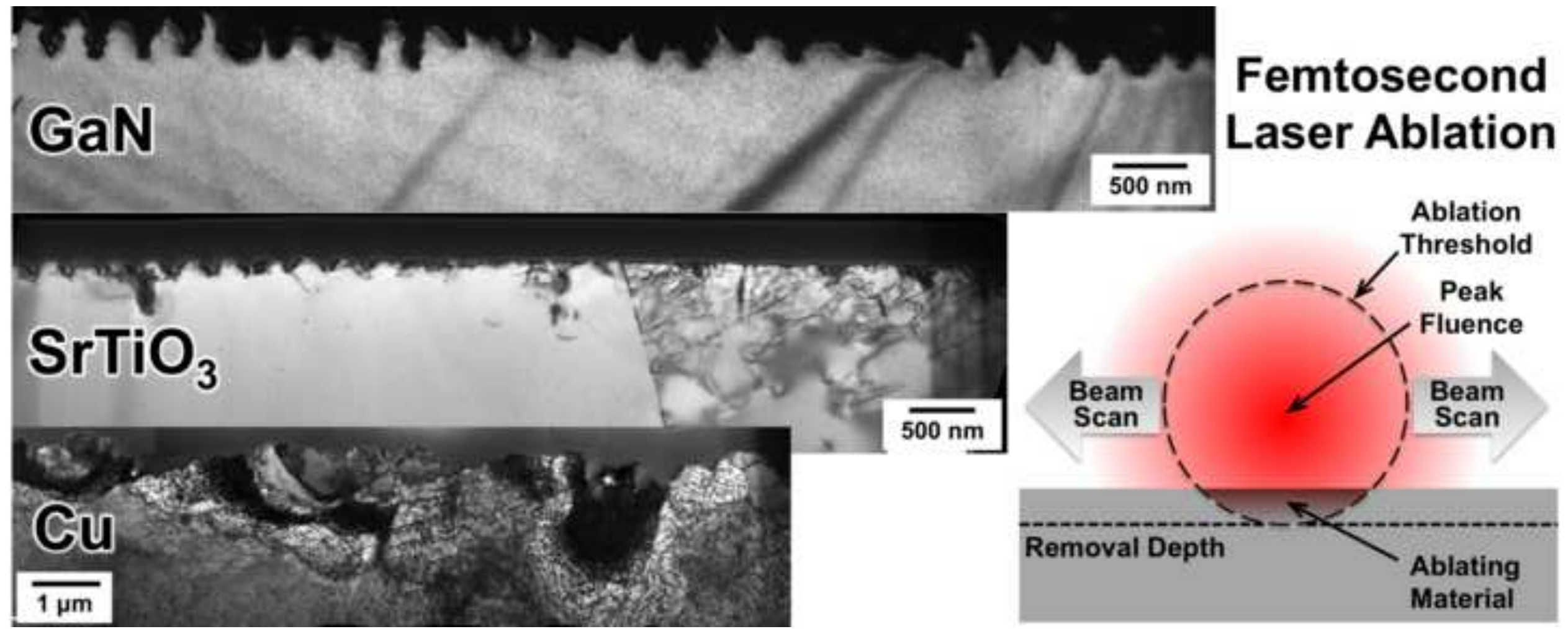

